\title{
Asthma severity in primary care asthma patients: a comparative study of four different approaches to severity classification
}

\author{
"Marianne Heibert Arnlinda,d, "Mika Nokela,a, , Per-Olof Ehrs ${ }^{a, c}$, *Eva Wikström Jonsson ${ }^{a, b}$ \\ a Centre for Allergy Research, Karolinska Institutet, Stockholm, Sweden. \\ ${ }^{\mathrm{b}}$ Department of Medicine Solna, Clinical Pharmacology Unit, Karolinska Institutet, Stockholm, Sweden \\ ' Lung and Allergy Research, Division of Physiology, National Institute of Environmental Medicine, Karolinska Institutet, Stockholm, Sweden \\ ${ }^{\mathrm{d}}$ Medical Management Centre, Department of Learning, Informatics, Management and Ethics, Karolinska Institutet, Stockholm, Sweden. \\ \# Joint first authors
}

Initial submission received 28th August 2007; re-submission received 2nd July 2008; revised version received 5th December 2009; accepted 2nd July 2010; online 9th September 2010

\begin{abstract}
Aims: To explore the factor structure of asthma severity and asthma control and to compare the results of different approaches to asthma severity classification on the distribution of costs of asthma medication.

Methods: Comparison of four different approaches to asthma severity classification and factor analysis of asthma control descriptors. A correlation analysis between costs and the different approaches to severity classification was performed.

Results: The factor analysis suggests that asthma control consists of at least two factors. Four approaches to severity classification were explored and all except the 'GINA EXPANDED' classification tended to place patients in the most severe category. The pharmaceutical costs varied between 0 and 75 SEK per day ( 0 and 5.31 GBP; 0 and 7.68 EURO ).

Conclusions: There is a considerable overlap between asthma control and asthma severity. None of the approaches used in this study present a superior satisfactory solution to the classification problem.

(C) 2010 Primary Care Respiratory Society UK. All rights reserved.

MH Arnlind et al. Prim Care Resp J 2010; 19(4): 383-389

doi:10.4104/pcrj.2010.00046
\end{abstract}

Keywords Asthma severity, classification, costs, asthma control

\section{Introduction}

Disease severity classification is crucial in research, providing an opportunity to compare important variables across different severity levels or to select populations. Severity classification is also fundamental for economic evaluation and development of reimbursement systems, and for prioritysetting and development of health care programs and guidelines.

The ideal system for asthma severity classification should be easily applicable in various clinical and research situations and should produce reliable and valid results. The most widely accepted severity classification in adult asthma patients so far is probably the Global Initiative for Asthma (GINA) guidelines. ${ }^{1}$ Nevertheless, the GINA classification has a number of limitations. ${ }^{2-4}$ Previous studies using the GINA severity classification system on patients on inhaled corticosteroid (ICS) treatment have suggested that the system tends to overestimate severity in these patients. ${ }^{5}$ In the revised GINA guidelines (Nov 2006), severity classification is regarded as suitable only for classification of patients who are not on ICS treatment - which seems to exclude severity classification of most asthmatics seeking care or participating in clinical trials. It is still unclear whether any classification system can be used to classify asthma severity reliably in patients receiving drug treatment. An alternative view of asthma severity has been suggested by Cockcroft and Swystun, ${ }^{6}$ where the minimum medication required to maintain control of asthma reflects the overall severity of the condition.

\footnotetext{
* Corresponding author: Dr Eva Wikström Jonsson, Clinical Pharmacology Unit, Department of Medicine (Solna), Karolinska Institutet, SE-171 76 Stockholm, Sweden. Tel: +46-8-517 71607 Fax: +46-8-33 1343 E-mail: eva.vikstrom-jonsson@karolinska.se
} 
The aims of this study were twofold:

- firstly, to explore the relationships between the components used to describe asthma control and disease severity, and to compare the results of four different approaches to asthma severity classification

- and secondly, to explore the impact of classifications on treatment costs

\section{Methods and Materials}

\section{Study design}

We used a database constructed from two primary care studies in which asthma-specific quality of life and conventional measures of clinical asthma and pharmaceutical costs were measured in a similar and standardised manner. ${ }^{7.8}$ Both studies were carried out during 2003 and 2004, in a similar fashion, and only data from the first of two visits was used in this study so that the outcomes would not be influenced by the trial interventions. The two separate studies as well as the present data analysis were approved by the regional ethics committee of the Karolinska Institutet.

\section{Study subjects}

The database constructed for this study consists of 246 patients in total. The inclusion and exclusion criteria in both studies are reported elsewhere. ${ }^{7.8}$

\section{Measures}

We measured asthma control with the Asthma Control Questionnaire (ACQ). ${ }^{9}$ Other instruments were not available in a Swedish version at the time for data collection. Disease specific Quality of Life (QoL) was measured with the Mini Asthma Quality of Life Questionnaire (MiniAQLQ). ${ }^{10}$

The costs of drugs per day were retrieved from the original databases. The cost of the daily dose of each drug was calculated per patient and summarised to total daily pharmaceutical costs per patient. Anti-asthmatic drugs and dosages used during the week preceding the visit were recorded. The details have been presented fully elsewhere. ${ }^{5}$

Asthma severity was classified according to four different approaches. The GINA guideline ${ }^{11}$ approach was used as a basis for three of the classifications. According to GINA, asthma severity is classified as intermittent, mild persistent, moderate persistent, or severe persistent, based on the combined assessments of symptoms, lung function and activity restrictions. Before treatment is begun, asthma severity classification rests entirely upon clinical features, whereas the classification of severity should be based on the clinical features present and the daily medication regimen when the patient is already on treatment.

\section{Classification methods used}

In this study, classification was performed both with and without consideration of current pharmaceutical treatment. The first approach that combines medical regimen and clinical features is referred to as 'GINA'. The second approach, where the medical regimen is neglected, is referred to as 'GINA-NAÏVE'. The third classification, referred to as 'GINA EXPANDED', was carried out with the intention of elaborating the GINA classification system by subdividing the fourth step, yielding two additional classes, on the basis of the following criteria:

Class $4=$ normal pulmonary function $\left(\mathrm{FEV}_{1} \%\right.$

predicted $>80 \%$ )

Class $5=$ impaired pulmonary function ( $\mathrm{FEV}_{1} \%$

predicted $<80 \%$ )

Class $6=$ treatment with oral corticosteroids

The fourth classification, referred to as 'TREATMENT INTENSITY', was carried out on the basis of two parameters: treatment steps, as defined in the GINA guidelines; and lung function. When the results of the two parameters differed, severity was defined by the parameter that yielded the most severe classification outcome. Lung function, measured as the forced expiratory volume in one second $\left(\mathrm{FEV}_{1}\right)$ expressed as $\%$ predicted, was classified into four categories according to the following:

$$
\begin{aligned}
& 1=\mathrm{FEV}_{1} \% \text { predicted }>80 \% \\
& 2=\mathrm{FEV}_{1} \% \text { predicted }>70 \% \leq 80 \% \\
& 3=\mathrm{FEV}_{1} \% \text { predicted }>60 \% \leq 70 \% \\
& 4=\mathrm{FEV}_{1} \% \text { predicted } \leq 60 \%
\end{aligned}
$$

On the basis of the ACQ scores, we identified patients having poor control and good control, ${ }^{12}$ using a score of 1 as a cutoff. Those patients scoring below 1 were considered to have good control and those above 1 poor control. ${ }^{12}$

\section{Statistical analysis}

Due to a skewed distribution of the variable "cost of drugs per day", the variable was transformed by taking the square root of costs. The distributions of the transformed cost were close to normal.

Comparison of the results from the different approaches to severity classification was made by calculating Cohen's kappa, in order to find out whether or not the different approaches yielded similar results.

\section{Factor analysis}

The objective of using factor analysis in this study was to determine whether asthma control variables, (FEV $1 \%$ predicted, diurnal asthma symptoms frequency, nocturnal asthma symptom frequency), activity impact of asthma, treatment intensity, and the four MiniAQLQ domains (symptoms, activities, emotions, and environment), would reduce to one or more common factors.

Factor analysis was performed by means of principal component analysis followed by varimax rotation. The number of factors chosen for the varimax rotation was based on the Eigenvalues of the factors in the principal component analysis, criterion Eigenvalue $>1$. Significant loading was 
considered to be greater than 0.40. Bartlett's Test of Sphericity and Kaiser-Meyer-Olkin Measure of Sampling Adequacy were performed to assess if the data were suitable for factor analysis.

\section{Results}

The demographics of the study population are shown in Table 1. In the study population, $67 \%$ of the 246 patients were females. The population mean age was 47.9 years, which is a little higher than in other studies on asthma. The smoking habits matched our expectations and the mean lung function after bronchodilation fell within the normal range. The pharmaceutical costs varied between 0 and 75.34 Swedish krona (SEK) and the median cost was lower in the nonsmoking group.

\section{Factor analysis of asthma descriptors}

On the basis of the Eigenvalues of the factors in the principal component analysis, a 2-factor model, which explained $54.2 \%$ of the variability, was chosen.

The second step of the factor analysis was to examine the variables with high loadings on each factor in order to identify the element that seemed to be common to those variables. The first factor extracted contained diurnal and nocturnal asthma symptoms, impact on activity and the four domains of the MiniAQLQ. The three first-mentioned variables are all related to asthma control assessment, and the four others to disease specific QoL. This factor accounted for approximately $42 \%$ of the total variance. The second factor contained two variables; $\mathrm{FEV}_{1} \%$ predicted and treatment intensity. These two variables are components in assessment of asthma severity. This factor accounts for approximately $11.5 \%$ of the total variance.

\section{Different approaches to classification of severity}

The different approaches yielded quite different proportions of persons identified as having mild (2-12\%), mild persistent (9-20\%), moderate (23-58\%), and severe asthma (12-66\%). Both the GINA-NAIVE and the TREATMENT INTENSITY classifications included more patients in the milder levels than the other two. The GINA method identified $89 \%$ of the subjects as having moderate or severe asthma. The GINAEXPANDED was the only method yielding symmetry in the distribution of subjects (see Figure 1).

When taking asthma control into account, the GINANAIVE and the TREATMENT INTENSITY classifications were still the methods that included the largest number of subjects in the milder levels. The GINA method still identified a large proportion of subjects as severe. The distribution of subjects in each category identified by the GINA EXPANDED lost some of its symmetry.

To evaluate further the extent of agreement between the three severity methods with the same number of categories, Kappa was calculated. GINA EXPANDED was left out, since it has more different categories. Table 2 illustrates that the agreement between the three compared methods was generally low. This indicates that the methods rate the same patients differently. In a worst case scenario, a patient might

Table 1. Demographic characteristics of the study population $(n=246)$.

\begin{tabular}{|c|c|c|c|c|}
\hline$x<$ & Total & Smokers & Non smokers & Ex smokers \\
\hline Sex (male/female); $n$ & $82 / 164$ & $8 / 37$ & $33 / 71$ & $39 / 56$ \\
\hline Age & 49.7 & 45.4 & 48.7 & 52.5 \\
\hline mean (min-max); years & $(18-87)$ & $(18-75)$ & $(18-87)$ & $(19-80)$ \\
\hline Asthma Control; mean (SD) & $1.53(1.04)$ & $1.67(1.03)$ & $1.47(1.05)$ & $1.49(0.96)$ \\
\hline \multicolumn{5}{|l|}{ Smoking habits, n (\%) } \\
\hline Smokers & $45(18.3)$ & 45 & - & - \\
\hline Ex-smokers & $95(38.6)$ & - & - & 95 \\
\hline Non-smokers & $104(42.3)$ & - & 104 & - \\
\hline Missing data & $2(0.8)$ & & & \\
\hline \multicolumn{5}{|l|}{ Lung function } \\
\hline $\mathrm{FEV}_{1}, \%$ of predicted; mean & 86 & 89 & 87 & 84 \\
\hline$(\min -\max ; n){ }^{+}$ & $(33-136 ; 196)$ & $(42-127 ; 39)$ & $(45-136 ; 79)$ & $(33-119 ; 76)$ \\
\hline \multicolumn{5}{|l|}{ Costs } \\
\hline Total daily costs of drugs per patient SEKmean/median & $11.89 / 10.24$ & $11.62 / 11.54$ & $11.64 / 9.52$ & $12.09 / 10.24$ \\
\hline Range, min-max & $0-75.34$ & $0-41.22$ & $0-75.34$ & $0-52.82$ \\
\hline \multicolumn{5}{|c|}{$\begin{array}{l}\mathrm{FEV}_{1}=\text { forced expiratory volume in one second. } \\
1 \mathrm{EUR}=9,12 \mathrm{SEK}(2003) ; 1 \mathrm{USD}=8,1 \mathrm{SEK}(2003) ; 1 \mathrm{GBP}=13,19 \mathrm{SEK} \text { (2003) } \\
\text { † Due to lack of spirometer at some PHCCS, pulmonary function data was no }\end{array}$} \\
\hline
\end{tabular}


$\mathrm{MH}$ Arnlind et al.

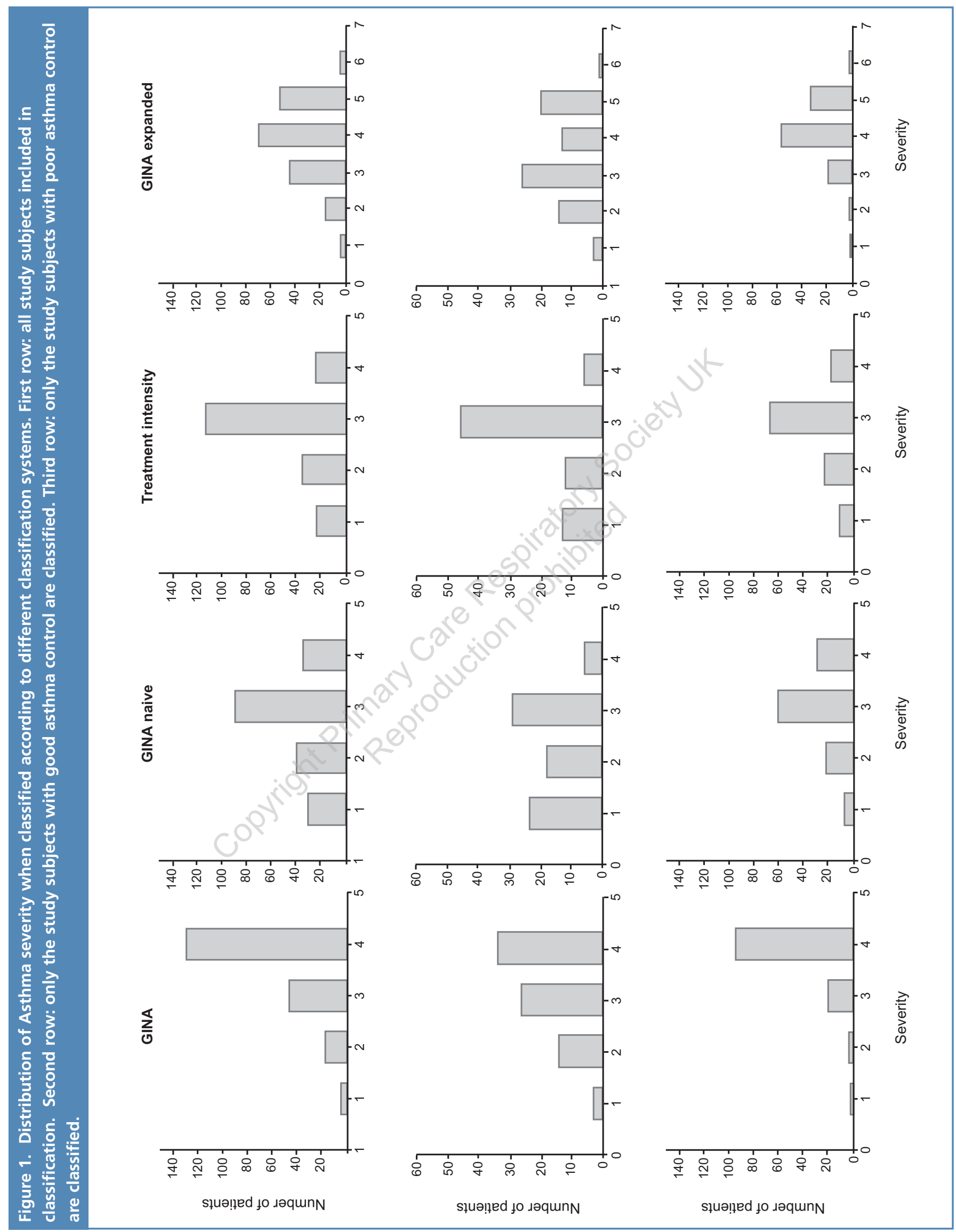




\begin{tabular}{|c|c|c|c|c|c|c|}
\hline \multirow{2}{*}{$\begin{array}{l}\text { Classification } \\
\text { methods } \\
\text { Subjects* }\end{array}$} & \multicolumn{3}{|c|}{$\begin{array}{l}\text { GINA } \\
\text { NAÏVE }\end{array}$} & \multicolumn{3}{|c|}{$\begin{array}{l}\text { TREATMENT } \\
\text { INTENSITY }\end{array}$} \\
\hline & all & good & poor & all & good & poor \\
\hline GINA & 0.046 & 0.039 & 0.023 & 0.041 & 0.074 & 0.008 \\
\hline GINA NAÏVE & - & - & - & 0.154 & 0.083 & 0.191 \\
\hline
\end{tabular}

be classified as having mild asthma by one method and as having severe asthma by another.

Exploring the impact of the classification on pharmaceutical treatment costs

The pharmaceutical costs varied between 0 and 75.34 (SEK) per day. The median cost was lower in the non-smoking group but the range between 0 and 75.34 (SEK) was the widest (Table 1).

The correlation between costs of medication and the

\begin{tabular}{|c|c|c|c|}
\hline \multirow{2}{*}{ Classification } & \multirow{2}{*}{$\begin{array}{l}\text { Costs } \\
\text { All Subjects }\end{array}$} & \multicolumn{2}{|c|}{ Subjects with } \\
\hline & & $\begin{array}{c}\text { Good asthma } \\
\text { control }\end{array}$ & $\begin{array}{c}\text { Poor asthma } \\
\text { control }\end{array}$ \\
\hline GINA & 0.393 & 0.243 & 0.402 \\
\hline GINA NAIVE & 0.170 & n.s & 0.221 \\
\hline GINA EXPANDED & 0.345 & 0.230 & 0.348 \\
\hline TREATMENT INTENSITY & 0.626 & 0.606 & 0.638 \\
\hline
\end{tabular}

different approaches to classify is presented in Table 3 . Treatment intensity has a major impact on costs $(0.626, p<$ $0.05)$ even when divided into good and poor asthma control.

Figure 2 shows the correlation between costs of asthma medication per day and the severity according to the four different methods. In the GINA classification, the costs of medication per day range from 0 to 46.08 SEK with a median of 11.46 SEK among severe asthmatics.

\section{Figure 2. Box plot of the costs (SEK) of asthma medication per day and the four asthma severity classifications. (Missing= no pulmonary function data) 1 EUR=9,12 SEK (2003). 1 USD=8,1 SEK (2003). 1 GBP= 13,19 SEK (2003).}
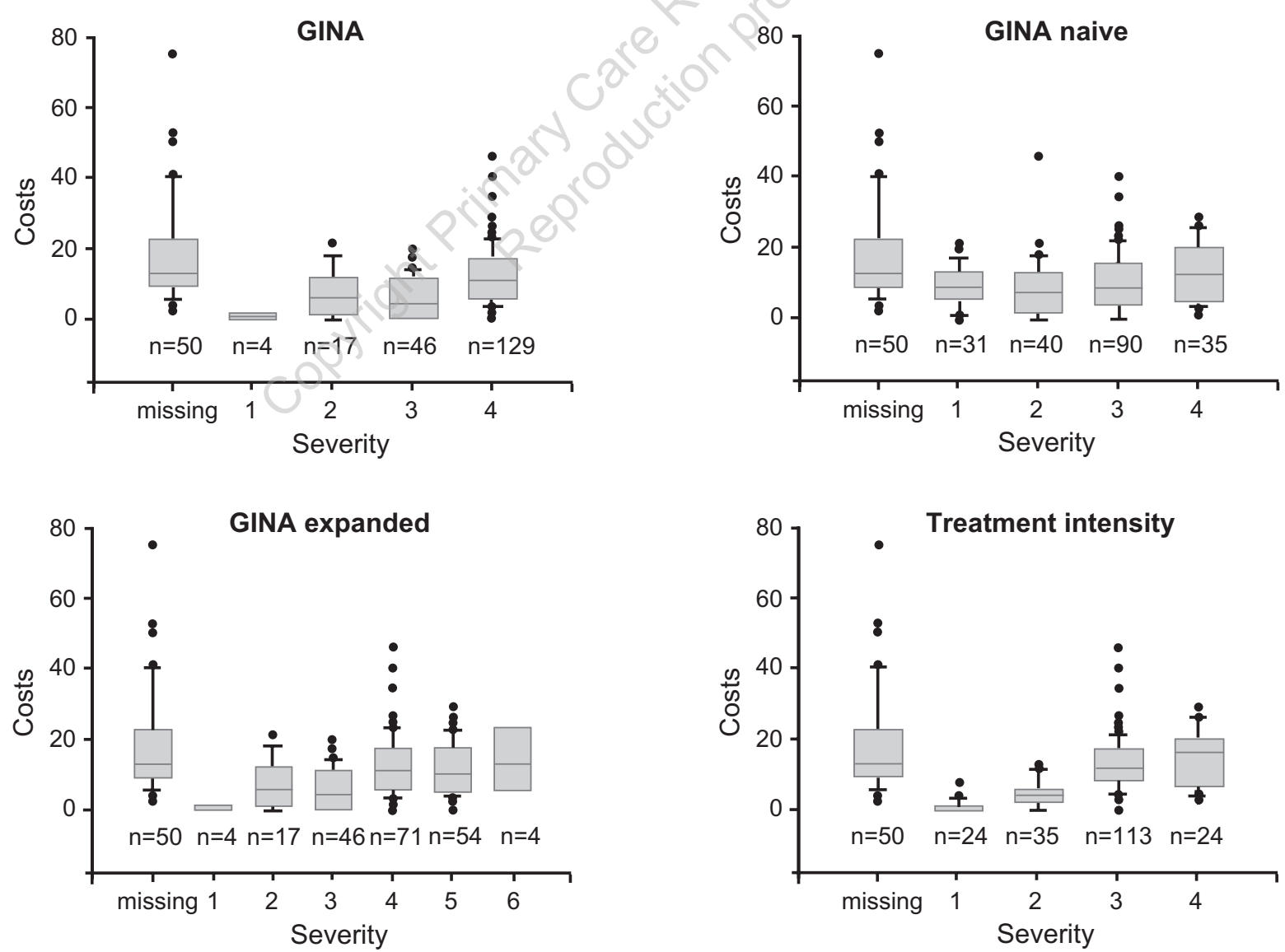


\section{Discussion}

The aims of this study were twofold: firstly, to explore relationships between the components of asthma control and disease severity, and to compare different approaches to severity classification of asthmatics already receiving treatment; and secondly, to explore the impact of these classifications on treatment costs.

To our knowledge this is the first study exploring the relationships between asthma control and severity in asthmatic patients who are actively being treated for their asthma and to test different approaches to classifying the severity of the patients' asthma in primary care. There is no gold standard for measuring or classifying asthma control. We measured asthma control with the ACQ. ${ }^{9}$ Other instruments to measure asthma control - for example, the Asthma Control Test $(\mathrm{ACT})^{13}$ - were not available in a Swedish version at the time for data collection. However, the impact of an alternative approach to measurement such as the ACT would probably not have been substantial since the item contents are relatively similar., ${ }^{9,13}$ Alternative approaches to classification of control have also been shown to have moderate agreement. $^{14}$

The factor analysis suggested a two-factor model that accounted for approximately $54 \%$ of the variability. The most prominent rotated factor ( $42 \%$ of variability) of the two included asthma control-related variables (diurnal asthma symptoms, nocturnal asthma symptoms, impact on activity) and disease specific QoL (the MiniAQLQ subscales). We labelled this factor "asthma control". The other factor (11.5\% of variability) included $\mathrm{FEV}_{1} \%$ predicted and treatment intensity. This factor we have labelled "asthma severity". Other similar studies have found a larger number of factors. ${ }^{15,16}$ Similar to the results of Juniper et al., ${ }^{15}$ our results suggest that lung function is clearly separate from symptoms and QoL.

Three out of the four different approaches we used to classify asthmatic patients already on treatment demonstrated a negative skewed result - i.e. a tendency to designate patients to the worst category. This can be understood in terms of a lack of discriminative ability in the classification methods or in terms of an inherent predisposition of the study population. In Scandinavia, treatment with ICS and long-acting $\beta_{2}$-agonists are started quite early in the course of the disease, ${ }^{17}$ which could account for some of the tendency to identify the patients as having severe asthma. Only the GINA EXPANDED classification did not yield these skewed results.

As seen in Figure 1, poor control seems to influence the results equally. This would suggest a lack of discriminative ability due to confounding. It has been claimed that important distinctions between asthma severity and asthma control exist. 18,19 Nevertheless, there is significant overlap between the parameters by which severity and control are defined. ${ }^{19}$ Thus, if asthma control is not taken into account, it is almost impossible to distinguish poorly controlled patients from patients with severe disease who manage to maintain good asthma control with extensive treatment. If one were to choose a classification method on the basis of discriminative ability, the choice should preferably be either the GINA EXPANDED or GINA NAIIVE classifications.

We have shown that the costs vary between the four approches. This highlights the importance of well defined classification systems when performing economic evaluations and creating reimbursement systems for health care. The correlation between pharmaceutical costs and severity using the different classification approaches shows that the method for classifying treatment intensity has a major influence on the distribution of cost data. However, there is a very large variation in costs between different patients considered as having equally severe disease, possibly indicating that clinical practice is a more important determinant of pharmaceutical costs than disease severity. ${ }^{5,20-22}$

An interesting view on the classification problem was presented by Cockcroft \& Swystun ${ }^{6}$ who suggest that the asthma severity of patients on treatment is reflected by the amount of medication needed to reach disease control. This view on severity is also adopted by Taylor et al..$^{23}$ and both the American Thoracic Society and The European Respiratory Society. ${ }^{24}$ However, our attempt to incorporate this notion by including treatment step in combination with the $\mathrm{FEV}_{1} \%$ predicted was unsuccessful. Other suggested disease markers such as exhaled nitric oxide and sputum eosinophilia might be useful in future classifications, but these measurements have hitherto not been included in routine use in primary care.

\section{Conclusion}

It is still unclear whether it is possible to classify reliably the severity of asthma in patients receiving drug treatment. In this study we explored the relationships between the components used to describe asthma control and compared the results of four different approaches to classifying disease severity in asthma patients on treatment. All of the classifications except the GINA EXPANDED system tended to allocate patients to the severest category. None of the approaches represent a superior satisfactory solution to the classification problem, and further research is needed to find a more appropriate classification.

\section{Acknowledgements}

The authors are grateful to Dr. Björn Ställberg and Professor Paul Hjemdahl for invaluable contribution to the main studies. We are also grateful to research nurse Lena Wahlberg for monitoring of the study sites and to the PHCCs for participating in the study.

\section{Funding}

The study was supported by the drug and therapeutics committees of the Stockholm County Council and Sörmland, the Stockholm County Council, the Vårdal Foundation and Centre for Allergy Research at Karolinska Institutet. 


\section{Conflict of interest}

No financial or other potential conflicts of interest related to the subject of the manuscript exist for any of the authors.

\section{References}

1. Bateman ED, Hurd SS, Barnes PJ, et al. Global strategy for asthma management and prevention: GINA executive summary. Eur Respir J 2008;31(1):143-78. http://dx.doi.org/ 10.1183/09031936.00138707

2. Cabana MD, Rand CS, Becher OJ, Rubin HR. Reasons for pediatrician nonadherence to asthma guidelines. Arch Pediatr Adolesc Med 2001;155(9):105762.

3. Doerschug KC, Peterson MW, Dayton CS, Kline JN. Asthma guidelines: an assessment of physician understanding and practice. Am J Respir Crit Care Med 1999;159(6):1735-41.

4. Roghmann MC, Sexton M. Adherence to asthma guidelines in general practices. J Asthma 1999;36(4):381-7. http://dx.doi.org/10.3109/02770909909068231

5. Arnlind $\mathrm{MH}$, Nokela M, Rehnberg C, Jonsson EW. The relationship between pharmaceutical costs, disease severity, and health-related quality of life in asthmatics in Swedish primary care. J Asthma 2006;43(8):585-91. http://dx.doi.org/10.1080/02770900600878305

6. Cockcroft DW, Swystun VA. Asthma control versus asthma severity. J Allergy Clin Immunol 1996;98(6 Pt 1):1016-18. http://dx.doi.org/10.1016/S00916749(96)80185-0

7. Ehrs PO, Nokela M, Stallberg B, Hjemdahl P, Wikstrom Jonsson E. Brief questionnaires for patient-reported outcomes in asthma: validation and usefulness in a primary care setting. Chest 2006;129(4):925-32. http://dx.doi.org/ 10.1378/chest.129.4.925

8. Nokela M, Heibert Arnlind M, Ehrs PO, Krakau I, Forslund L, Wikstrom Jonsson E. The Influence of Structured Information and Monitoring on the Outcome of Asthma Treatment in Primary Care: A Cluster Randomized Study. Respiration 2010;79:388-94. http://dx.doi.org/ 10.1159/000235548

9. Juniper EF, O'Byrne PM, Guyatt GH, Ferrie PJ, King DR. Development and validation of a questionnaire to measure asthma control. Eur Respir J 1999;14(4):902-07.

10. Juniper EF, Guyatt GH, Cox FM, Ferrie PJ, King DR.Development and validation of the Mini Asthma Quality of Life Questionnaire. Eur Respir J 1999;14(1):32-8.

11. 2004 Update: Workshop Report, Global Strategy for Asthma Management and Prevention: From the Global Strategy for Asthma Management and Prevention, Global Initiative for Asthma (GINA) 2004. http://www.ginasthma.com/ Guidelineltem .asp?intld=987
12. Juniper EF, Bousquet J, Abetz L, Bateman ED. Identifying 'well-controlled' and 'not well-controlled' asthma using the Asthma Control Questionnaire. Respir Med 2006;100(4):616-21. http://dx.doi.org/10.1016/j.rmed.2005.08.012

13. Nathan RA, Sorkness CA, Kosinski M, et al. Development of the asthma control test: a survey for assessing asthma control. J Allergy Clin Immunol 2004;113(1):5965.http://dx.doi.org/10.1016/j.jaci.2003.09.008

14. Thomas M, Kay S, Pike J, et al. The Asthma Control Test (ACT) as a predictor of GINA guideline-defined asthma control: analysis of a multinational cross-sectional survey. Prim Care Resp J 2009;18(1):41-9.

15. Juniper EF, Wisniewski ME, Cox FM, Emmett AH, Nielsen KE, O'Byrne PM. Relationship between quality of life and clinical status in asthma: a factor analysis. Eur Respir J 2004;23(2):287-91. http://dx.doi.org/10.1183/09031936. 04.00064204

16. Schatz M, Mosen D, Apter AJ, et al. Relationships among quality of life, severity, and control measures in asthma: an evaluation using factor analysis. J Allergy Clin Immuno/ 2005;115(5):1049-55. http://dx.doi.org/10.1016/j.jaci.2005.02.008

17. Sverige. Socialstyrelsen. Socialstyrelsens riktlinjer för förebyggande, diagnostik, behandling och rehabilitering av astma och KOL. Remissversion ed. Stockholm: Socialstyr.; 2003.

18. Vollmer WM. Assessment of asthma control and severity. Ann Allergy Asthma Immunol 2004;93(5):409-13; quiz 14-6, 92.

19. Fuhlbrigge AL. Asthma severity and asthma control: symptoms, pulmonary function, and inflammatory markers. Curr Opin Pulm Med 2004;10(1):1-6. http://dx.doi.org/10.1097/00063198-200401000-00002

20. Lundborg CS, Wahlstrom R, Dall'Alba G. Ways of experiencing asthma management. Variations among general practitioners in Sweden. Scand J Prim Health Care 1999;17(4):226-31. http://dx.doi.org/10.1080/028134399750002458

21. Eckerlund I. Essays on the Economics of medical Practice Variations. Stockholm: Stockholm School of Economics; 2001.

22. Cochrane GM , Horne R, Chanez P. Compliance in asthma. Respiratory Medicine 1999;93:763-9. http://dx.doi.org/10.1016/S0954-6111(99)90260-3

23. Taylor DR, Bateman ED, Boulet L-P, et al. A new perspective on concepts of asthma severity and control. Eur Respir J 2008;32:545-54. http://dx.doi.org/ 10.1183/09031936.00155307

24. Reddel HK, Taylor DR, Bateman ED, et al. on behalf of the American Thoracic Society/European Respiratory Society Task Force on Asthma Control and Exacerbations: Standardizing Endpoints for Clinical Asthma Trials and Clinical Practice. Am J Respir Crit Care Med 2009;180(1):59-99. http://dx.doi.org/ 10.1164/rccm.200801-060ST

\section{Available online at http://www.thepcrj.org}

